\title{
Genetic Characterization of Hepatitis C Viruses in HIV Positive People who Inject Drugs, Dhaka, Bangladesh
}

Mustafizur Rahman ${ }^{\star}$, Ezazul Islam Chowdhury ${ }^{1}$, Masud Reza ${ }^{1}$, Md Shah Alam¹, M. Safiullah Sarker ${ }^{1}$, Mokibul Hassan Afrad ${ }^{1}$, Muntasir Alam $^{1}$, M. Ziaur Rahman ${ }^{1}$, Mahmoud Reza Pourkarim² and Tasnim Azim ${ }^{1}$

${ }^{1}$ Centre for HIV and AIDS, International Centre for Diarrhoeal Disease Research, Bangladesh

${ }^{2}$ Laboratory of Clinical Virology, Rega Institute for Medical Research, University of Leuven, Belgium

\begin{abstract}
We investigated the HCV genotypes in HIV positive people who inject drugs (PWID) identified in Dhaka Bangladesh in 2003. Genetic analyses revealed that the PWIDs shared closely related HIV strains subtype C genotypes but HCV genotypes in them were distantly related. This indicates that the mode of transmission of HIV and HCV infections in PWIDs might be different.
\end{abstract}

\section{Keywords: HIV; HCV; Co-infection; Genotype; PWIDs; Bangladesh}

Bangladesh has an estimated 20,000-40,000 people who inject drugs (PWIDs) who are scattered over different areas of the country [13]. Prevalence of hepatitis $C$ virus was much higher in this group (more than $50 \%$ in some cities) [4] than in the general population (0.8\%) [5]. Similarly, HIV prevalence in Bangladesh is high in PWIDs compared to other most-at-risk population (MARP). Routine surveillance conducted among MARP including sex workers, PWIDs, males having sex with males, has shown that the overall HIV prevalence until 2007 was less than $1 \%$. However, the HIV prevalence in PWIDs particularly in Dhaka was much higher (7\% in an urban area). A cohort study conducted among PWID in two neighbourhoods in Dhaka, Bangladesh during 2002-2007 reported that HIV and hepatitis C virus (HCV) prevalence were $5.9 \%$ and $66.8 \%$ respectively at baseline [4].

While HIV may be transmitted through multiple routes, it is believed that HCV in PWIDs is transmitted mainly via percutaneous exposure. Thus, the risk factors for HIV and HCV infections among PWIDs may differ and therefore lead to the different prevalence for the two infections. Studies on genetic characterization of HIV strains in PWIDs indicate that most of the HIV strains in PWIDs were subtype $\mathrm{C}$ which are closely related to strains from India, Middle East and East Asia [6]. However, it is yet to unveil the distribution of hepatitis $C$ virus genotypes in PWIDs and the possible origin(s) of the viruses. Since intervention programs to prevent further escalation of the HIV and/ or HCV epidemic are very important, it is required that HIV-HCV coinfection as well as their genetic characterization are understood. Here we describe the genetic variation of HIV-HCV in PWIDs in two urban areas in Dhaka.

Blood samples were obtained from HIV-HCV co-infected sero-positive PWIDs who participated in a cohort study in two neighbourhoods in Dhaka. Viral RNA was extracted using the QIAamp Viral RNA Mini kit (QIAGEN, Leusden, the Netherlands). PCR based detection and phylogenetic analysis of HIV genetic material was done based on gag gene segments as previously described by Sarker et al. [6]. HCV RNA was detected by RT-PCR with primers specific to $5^{\prime}$ UTR of $\mathrm{HCV}$ genome. PCR positive samples were genotyped by sequencing of core genes using ABI Prism BigDye Terminator Cycle Sequencing Reaction kit (Applied Biosystem) [7]. The sequences were submitted to GenBank database under the following accession numbers JQ888223JQ888233 and JQ668327-JQ668332, EF999807.

A total of 31 blood samples were analysed for HCV and HIV genes out of which $7 \mathrm{HIV}$ and $17 \mathrm{HCV}$ genes could be amplified. Genotyping data of HCV based on core gene revealed that 11 of them were genotype $3 \mathrm{a}(65 \%), 4$ genotype $3 \mathrm{~b}(24 \%)$ and 2 genotype $1 \mathrm{~b}(11 \%)$. The prevalence of HCV genotypes $3 \mathrm{a}$ and $3 \mathrm{~b}$ and HIV subtype $\mathrm{C}$ in Bangladesh is comparable to that observed in other neighbouring countries, India and Myanmar [8-10]. Phylogenetic analyses of partial core gene seqeunces indicated that HCV strains clustered in different genotypes: $3 \mathrm{a}, 3 \mathrm{~b}$ and $1 \mathrm{~b}$ and were closely to the Asian HCV strains (Figure 1A). On the other hand, phylogenetic tree (Figure 1B) based on partial gag genes of HIV strains isolated from the same individuals placed them in the same cluster belonging to HIV subtype C. This indicates that although PWIDs shared genetically close relative HIV strains, the HCV strains were different.

There are several limitations that need to be addressed in future studies. The first limitation is that a major proportion of the study samples could not be characterized by PCR. The reason as to why PCR did not amplify much HIV/HCV genetic material might be because the virus copies in the PCR negative samples were at undetectable level due to inappropriate preservation of samples. Second, we analyzed very low numbers of samples. Inclusion of more subjects from different population groups (not just PWID) in future studies would give us more information on circulating HCV/HIV genotypes and their possible interactions in terms of anti-viral medications in these coinfected individuals.

\section{Acknowledgement}

This research study was funded by icddr,b and its donors which provide unrestricted support to icddr,b for its operations and research. Current donors providing unrestricted support include: Australian Agency for International Development (AusAID), Government of the People's Republic of Bangladesh Canadian International Development Agency (CIDA), Swedish International

*Corresponding author: Mustafizur Rahman, Ph.D, Centre for HIV and AIDS, icddr,b, 68, Shaheed Tajuddin Ahmed Sharani, Dhaka-1212, Bangladesh, Phone: +8802-9840523-32; Ext-3454; Fax: +8802-8812529; E-mail: mustafizur@icddrb.org

Received March 08, 2012; Accepted August 28, 2012; Published August 31, 2012

Citation: Rahman M, Chowdhury El, Reza M, Alam MS, Sarker MS, et al (2012) Genetic Characterization of Hepatitis C Viruses in HIV Positive People who Inject Drugs, Dhaka, Bangladesh. J AIDS Clinic Res 3:165. doi:10.4172/21556113.1000165

Copyright: () 2012 Rahman M, et al. This is an open-access article distributed under the terms of the Creative Commons Attribution License, which permits unrestricted use, distribution, and reproduction in any medium, provided the original author and source are credited. 
Citation: Rahman M, Chowdhury El, Reza M, Alam MS, Sarker MS, et al. (2012) Genetic Characterization of Hepatitis C Viruses in HIV Positive People who Inject Drugs, Dhaka, Bangladesh. J AIDS Clinic Res 3:165. doi:10.4172/2155-6113.1000165

Development Cooperation Agency (Sida), and the Department for International Development, UK (DFID). We gratefully acknowledge these donors for their support and commitment to icddr,b's research efforts.

\section{References}

1. Mathers BM, Degenhardt L, Phillips B, Wiessing L, Hickman M, et al. (2008) Global epidemiology of injecting drug use and HIV among people who inject drugs: a systematic review. Lancet 372: 1733-1745.

2. National AIDS Committee (2006) UNGASS Indicators Country Report. Dhaka: Ministry of Health and Family Welfare, Govt. of Bangladesh.

3. Reddy A, Hoque MM, Kelly R (2008) HIV transmission in Bangladesh: an analysis of IDU programme coverage. Int J Drug Policy 19: S37-S46.

4. Azim T, Chowdhury El, Reza M, Faruque MO, Ahmed G, et al. (2008) Prevalence of infections, HIV risk behaviors and factors associated with HIV infection among male injecting drug users attending a needle/syringe exchange program in Dhaka, Bangladesh. Subst Use Misuse 43: 2124-2144.

5. Mahtab MA, Rahman S, Karim MF, Khan M, Foster G, et al. Epidemiology of hepatitis $B$ virus in Bangladeshi general population. Hepatobiliary Pancreat Dis
Int 7: 595-600.

6. Sarker MS, Rahman M, Yirrell D, Campbell E, Rahman AS, et al. (2008) Molecular evidence for polyphyletic origin of human immunodeficiency virus type 1 subtype $C$ in Bangladesh. Virus Res 135: 89-94.

7. Sandres-Saune K, Deny P, Pasquier C, Thibaut V, Duverlie G, et al. (2003) Determining hepatitis $C$ genotype by analyzing the sequence of the NS5b region. J Virol Methods 109: 187-193.

8. Narahari S, Juwle A, Basak S, Saranath D (2009) Prevalence and geographic distribution of Hepatitis C Virus genotypes in Indian patient cohort. Infect Genet Evol 9: 643-645.

9. Ponamgi SP, Rahamathulla S, Kumar YN, Chandra M, Lakshmi N, et al. (2009) Prevalence of hepatitis C virus (HCV) coinfection in HIV infected individuals in south India and characterization of HCV genotypes. Indian J Med Microbio 27: 12-16.

10. Lwin AA, Shinji T, Khin M, Win N, Obika M, et al. (2007) Hepatitis C virus genotype distribution in Myanmar: Predominance of genotype 6 and existence of new genotype 6 subtype. Hepatol Res 37: 337-345.

\section{A. HCV-core}

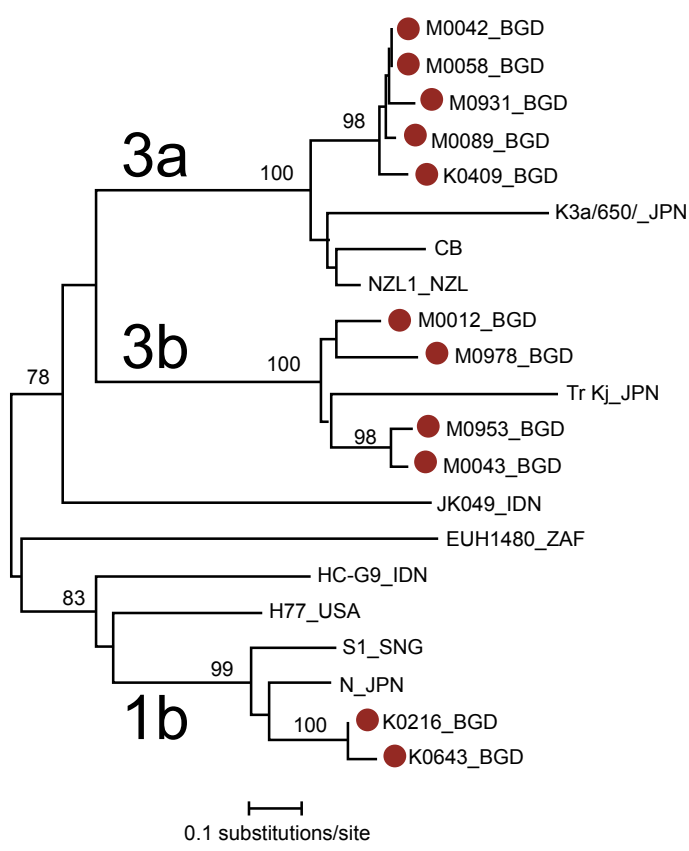

\section{B. HIV-gag}

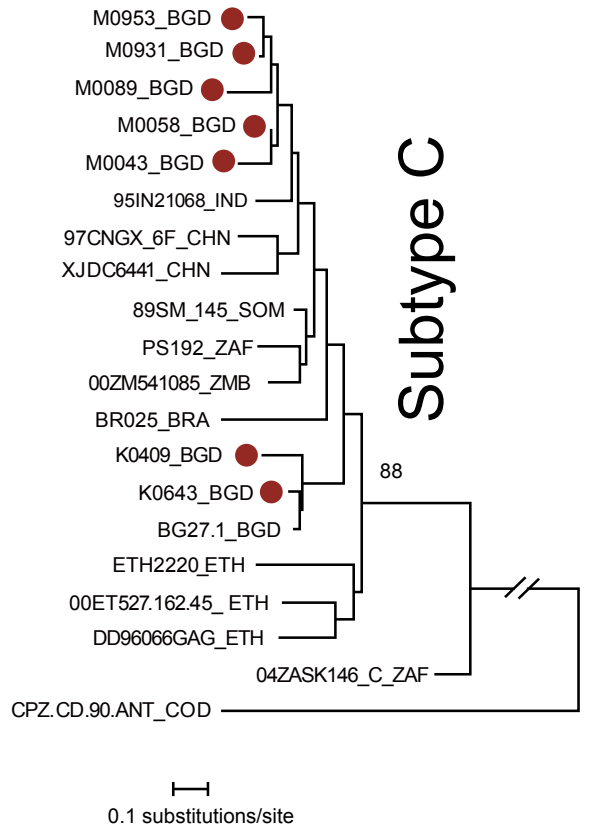

Figure 1: Phylogenetic trees of partial nucleotide sequences of A. HCV core and B. HIV gag genes. The numbers adjacent to the nodes represent the percentage of bootstrap support (of 1000 replicates) for the clusters to the right of the node. Bootstrap values lower than $70 \%$ were not shown. The circles indicate Bangladeshi study strains. 